American J. of Engineering and Applied Sciences 2 (1): 50-53, 2009

ISSN 1941-7020

(C) 2009 Science Publications

\title{
ANN Based Prediction of Effect of Reinforcements on Abrasive Wear Loss and Hardness in a Hybrid MMC
}

\author{
${ }^{1}$ Sathyabalan, P., ${ }^{2}$ V. Selladurai and ${ }^{3}$ P. Sakthivel \\ ${ }^{1,3}$ Department of Mechanical Engineering, Kumaraguru College of Technology, Coimbatore, India \\ ${ }^{2}$ Department of Mechanical Engineering, Coimbatore Institute of Technology, Coimbatore, India
}

\begin{abstract}
Problem statement: The reinforcements added to an alloy lead to variation in properties. The content and size of the reinforcement influences the properties of composites. Very little research has been carried out in hybrid composites. Work on hybrid LM6 aluminium alloy metal matrix composites (MMC) with flyash and $\mathrm{SiC}$ has been initiated here. The effect of the four parameters, size and weight of the reinforcements on the hardness and wear loss has been studied. Approach: Artificial neural networks, from the artificial intelligence family, is a type of information processing system, based on modeling the neural system of human brain. The effect of the parameters was investigated using ANN. Central composite rotatable method of design of experiments was used to arrive at the combination and the number of specimens. The specimens were prepared using the liquid metallurgy route and tested. Pin-on-disc apparatus was used for determining wear. Rockwell hardness on C scale was determined. The data from the experiments were used for training and testing the network. Results: The accuracy in ANN prediction was appreciable with the error estimated for wear loss and hardness being less than $2 \%$. Conclusions/Recommendations: The ANN prediction is quick and economical way of estimating the properties.
\end{abstract}

Key words: LM6 Aluminium alloy, SiC, Flyash, Dry sliding wear

\section{INTRODUCTION}

Metal Matrix Composites possess high specific strength, better stiffness and wear resistance in addition to high service temperatures. With particle reinforcements, metal matrix composites exhibit isotropic properties. Aluminium alloys with various reinforcements have been considered for applications in automotive components. The hardness and wear resistance of alloys improve with the addition of hard reinforcement like SiC. The wear resistance of Aluminium alloys with $\mathrm{SiC}$ particles has been studied in detail ${ }^{[1]}$. However the addition of reinforcement leads to increase in the cost of the product. Flyash which is a waste coal combustion byproduct from thermal power plants has been used as a filler material or functional extender in plastics, paints, resins and adhesives. The addition of flyash is also found to be effective in improving the resistance to wear of $\mathrm{Al}$ alloys $^{[2]}$. Moreover the addition of flyash reduces the density of the composite ${ }^{[3]}$, leading to structural applications where weight saving is of importance. Increase in percentage by weight of flyash leads to reduction in wear rate ${ }^{[3]}$. Increase in volume percentage of $\mathrm{SiC}$ reduces weight loss in aluminium alloys ${ }^{[4]}$. The wear loss in aluminium alloy composite was found to reduce with the size of $\mathrm{SiC}$ particle reinforcement ${ }^{[5]}$.

Not much work has been done on hybrid composites, with $\mathrm{SiC}$ and flyash as reinforcements. In the present investigation, an attempt has been made to predict the effect of addition of $\mathrm{SiC}$ and flyash on the dry sliding wear behavior of LM6 aluminium alloy. The effect of the size and percentage by weight of the reinforcements has been considered in the wear study. Powder metallurgy ${ }^{[6]}$, stir casting $^{[7]}$, pressure infiltration $^{[8]}$, squeeze casting ${ }^{[9]}$ are the techniques used in the manufacture of MMCs. Stircasting is the economical way of getting good distribution of reinforcements.

Neural networks have been successfully used to predict tensile and density properties ${ }^{[10]}$, as also the wear and surface roughness in metal matrix composites $^{[11]}$.

\section{MATERIALS AND METHODS}

Preparation of specimens: The flyash for the study has been procured from Raichur thermal powerplant in Karnataka. Aluminium alloy was first melted in an electric furnace. Flyash and $\mathrm{SiC}$, preheated to a

Corresponding Author: Sathyabalan, P., Department of Mechanical Engineering, Kumaraguru College of Technology, Coimbatore-641 006, India Tel: 919443913898 
temperature of about $600^{\circ} \mathrm{C}$, were added to the molten metal at $720^{\circ} \mathrm{C}$ and stirred continuously. The stirring was done at $600 \mathrm{rpm}$ for 5-7 min. Magnesium was added in small amounts during stirring to increase the wetting. The melt with reinforcement was poured into permanent metallic mould. Cylindrical pins of length $30 \mathrm{~mm}$ and diameter $10 \mathrm{~mm}$ were machined.

Wear testing: The wear specimens were tested on Ducom, Bangalore make Pin-on-disc apparatus. The specimen pin was pressed against a rotating EN32 steel disc (Fig. 1.) having hardness of $65 \mathrm{HRC}$ by a constant $8 \mathrm{~kg}$ force. The load has to be given at the other end of the arm that carries pin. The speed and distance travelled were maintained constant at $1 \mathrm{~m} \mathrm{sec}^{-1}$ and $1500 \mathrm{~m}$. The specimens were weighed in a single pan weighing machine having a least count of $0.0001 \mathrm{~g}$. After sliding wear test the specimen were cleaned with acetone and then weighed. The difference in weight before and after the wear test gives the loss of material. The indicator for the wear in microns of the apparatus should indicate zero. This will ensure proper loading of the arm.

Central composite Rotatable design: A planned way of performing the experiments leads to better results. Design of experiments helps in arriving at the proper combination of the various parameters ${ }^{[12]}$. It also helps us in arriving at the number of experiments to be conducted. As neural networks are trained, their success depends on the effectiveness of the data used in training. Central composite rotatable design with four factors and five levels was chosen to arrive at the possible combination of variables. Table 1 gives the limits of process parameters. The reinforcements are taken as percentage of weight of base alloy. The size of $\mathrm{SiC}$, the weight fraction of $\mathrm{SiC}^{[13]}$, the size and weight fraction $^{[14]}$ of flyash which are bound to influence the wear behavior are the parameters. The reinforcements are sieved and the mean size of the range in microns is used. The limits of the various parameters have been arrived from literature. A high percentage of the reinforcements have been experimentally found to be difficult in fabricating good samples. Also the wear resistance does not improve after a certain percentage by weight as the volume of reinforcement becomes high.

The limits of the process parameters have been arrived from the formula

$$
X_{i}=\frac{2\left(2 X-\left(X_{\max }+X_{\text {min }}\right)\right)}{\left(X_{\text {max }}-X_{\text {min }}\right)}
$$

where $X_{i}$ is the required coded value of a variable $X, X$ is any value of the variable from $X_{\min }$ to $X_{\max }, X_{\min }$ is the lower limit of the variable and $X_{\max }$ is the upper limit of the variable. The coded values for intermediate values have been calculated using Eq. 1 .

The design matrix along with the responses is given in Table 2. The weight loss in material due to wear and Rockwell hardness are the two responses which have been experimentally determined.

Neural network: ANN has been used to model non linear processes in manufacturing. The advantage of ANN is storing samples with distributed coding, forming a trainable non linear system. The data for training and testing have been taken from experiments conducted as per DOE. Data of 18 samples were used for training, while the remaining samples data were used for testing. For training, Levenberg-Marquardt algorithm, though computationally complex, has been used as it is faster ${ }^{[14]}$. Sigmoid activation function has been used with coded values. The neural network simulation has been done using Matlab. The simple neural network structure used is shown in Fig. 2. The input layer has four neurons, representing the four parameters. The input neurons receive the input from the environment. The output neurons send output out of the system. The output neurons represent the wear loss and hardness. The hidden neurons have the input and output of the system. As there is no method to arrive at the number of neurons in the hidden layer, it has to be found experimentally.

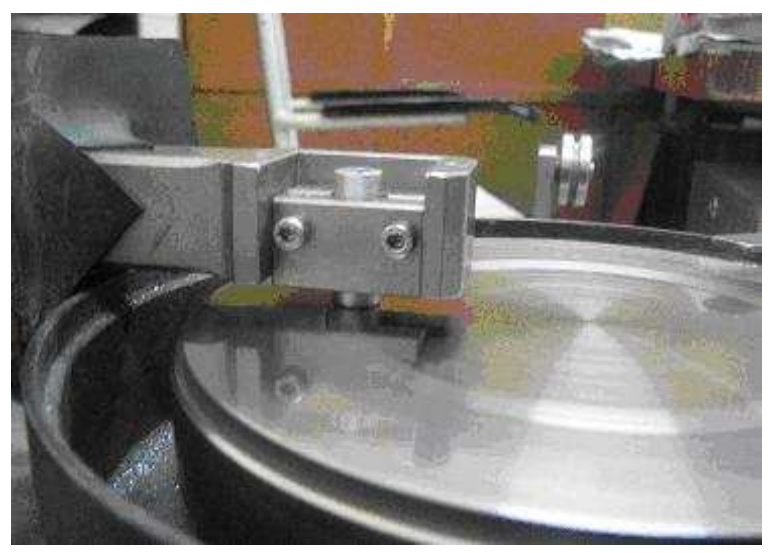

Fig. 1: Pin pressing against rotating steel disc 
Am. J. Engg. \& Applied Sci., 2 (1): 50-53, 2009

Table 1: Limits of process parameters

\begin{tabular}{llllllll}
\hline & & \multicolumn{5}{c}{ Factor Levels } \\
Parameter & Units & Notation & -2 & -1 & 0 & +1 & +2 \\
\hline Flyash grain size range & $\mu \mathrm{m}$ & $\mathrm{F}_{\mathrm{s}}$ & $0-40$ & $40-106$ & $106-150$ & $150-180$ & $180-250$ \\
SiC grain size range & $\mu \mathrm{m}$ & $\mathrm{S}_{\mathrm{s}}$ & $0-25$ & $25-40$ & $40-63$ & $63-90$ & $90-106$ \\
Flyash weight & $\%$ & $\mathrm{~F}$ & 2 & 4 & 6 & 8 & 10 \\
SiC weight & $\%$ & $\mathrm{~S}$ & 2 & 4 & 6 & 8 & 10 \\
\hline
\end{tabular}

Table 2: Design matrix and responses

\begin{tabular}{|c|c|c|c|c|c|c|}
\hline Specimen & $F_{s}$ & $\mathrm{~S}_{\mathrm{s}}$ & $\mathrm{F}$ & $\mathrm{S}$ & $\begin{array}{l}\text { Response 1: } \\
\text { Wear loss (mg) }\end{array}$ & $\begin{array}{l}\text { Response 2: } \\
\text { Hardness (HRC) }\end{array}$ \\
\hline$\overline{\mathrm{S} 1}$ & -1 & -1 & -1 & -1 & 20.4 & 117 \\
\hline S2 & +1 & -1 & -1 & -1 & 23.4 & 132 \\
\hline S3 & -1 & +1 & -1 & -1 & 18.6 & 128 \\
\hline S4 & +1 & +1 & -1 & -1 & 25.6 & 134 \\
\hline S5 & -1 & -1 & +1 & -1 & 24.0 & 120 \\
\hline S6 & +1 & -1 & +1 & -1 & 32.0 & 135 \\
\hline S7 & -1 & +1 & +1 & -1 & 18.2 & 150 \\
\hline S8 & +1 & +1 & +1 & -1 & 30.0 & 130 \\
\hline S9 & -1 & -1 & -1 & +1 & 26.0 & 105 \\
\hline $\mathrm{S} 10$ & +1 & -1 & -1 & +1 & 27.6 & 126 \\
\hline S11 & -1 & +1 & -1 & +1 & 25.1 & 123 \\
\hline S12 & +1 & +1 & -1 & +1 & 29.0 & 145 \\
\hline S13 & -1 & -1 & +1 & +1 & 36.0 & 102 \\
\hline S14 & +1 & -1 & +1 & +1 & 38.0 & 118 \\
\hline S15 & -1 & +1 & +1 & +1 & 33.5 & 137 \\
\hline S16 & +1 & +1 & +1 & +1 & 38.2 & 125 \\
\hline S17 & -2 & 0 & 0 & 0 & 24.2 & 128 \\
\hline S18 & +2 & 0 & 0 & 0 & 34.0 & 175 \\
\hline S19 & 0 & -2 & 0 & 0 & 25.2 & 102 \\
\hline S20 & 0 & +2 & 0 & 0 & 21.6 & 136 \\
\hline S21 & 0 & 0 & -2 & 0 & 21.1 & 120 \\
\hline S22 & 0 & 0 & +2 & 0 & 35.0 & 108 \\
\hline S23 & 0 & 0 & 0 & -2 & 22.1 & 129 \\
\hline S24 & 0 & 0 & 0 & +2 & 38.6 & 125 \\
\hline S25 & 0 & 0 & 0 & 0 & 20.0 & 114 \\
\hline
\end{tabular}

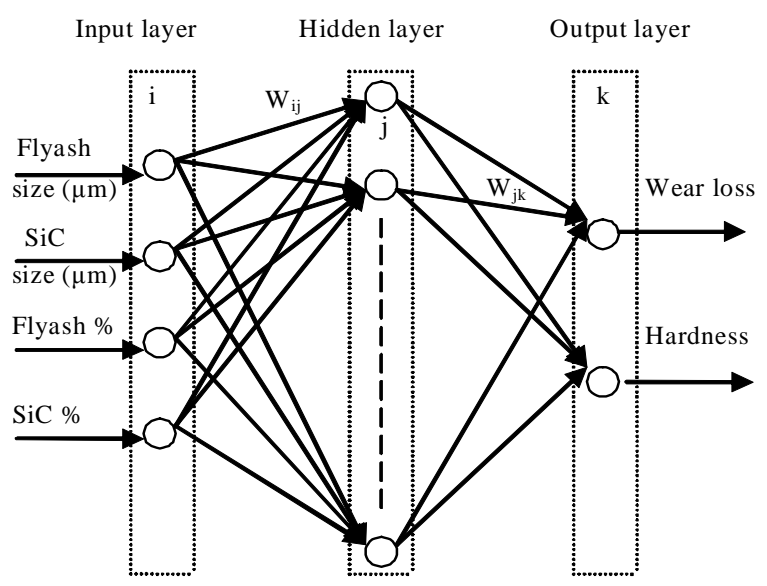

Fig. 2: Structure of the neural network
Table 3: Comparision of predicted with actual values

\begin{tabular}{lcccccc}
\hline & Weight loss (mg) & \multicolumn{2}{l}{ Hardness (HRC) } & Percentage error \\
& - & & & \\
Specimen & Actual & Predicted & Actual & Predicted & Wear loss & Hardness \\
\hline S1 & 20.4 & 20.29 & 117 & 116.76 & 0.56 & 0.200 \\
S2 & 23.4 & 23.10 & 132 & 130.08 & 1.29 & 1.460 \\
S4 & 25.6 & 25.57 & 134 & 134.03 & 0.13 & -0.020 \\
S7 & 18.2 & 18.20 & 150 & 148.98 & -0.13 & 0.680 \\
S8 & 30.0 & 29.99 & 130 & 129.43 & 0.04 & 0.440 \\
S14 & 38.0 & 38.07 & 118 & 118.60 & -0.18 & -0.500 \\
S16 & 38.2 & 38.00 & 125 & 125.00 & 0.53 & 0.004 \\
\hline
\end{tabular}

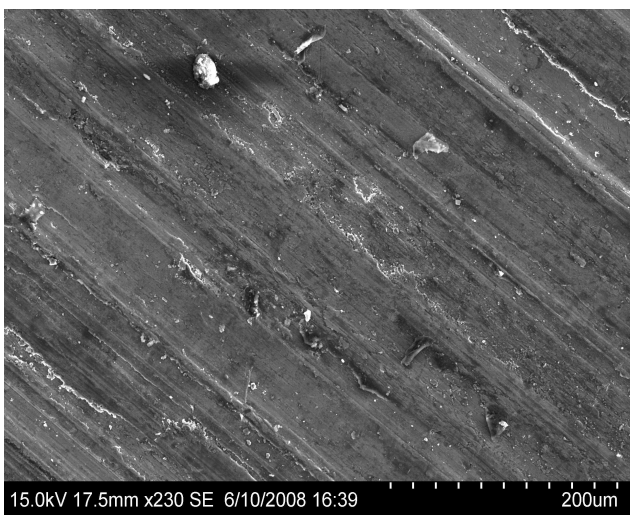

Fig. 3: SEM of the worn surface of pin

\section{RESULTS}

A feed forward, multi layer perception neural network has been designed to predict the sliding wear loss and also the hardness of flyash and $\mathrm{SiC}$ reinforced LM6 aluminium alloy. The network has a single hidden layer with six neurons. The comparison of the actual values of weight loss due to abrasive sliding wear and the Rockwell hardness for the seven test samples with the predicted ones is shown in Table 3. The MSE for training and validation has been found to be 0.00875092 .

\section{DISCUSSION}

The values for weight loss and hardness predicted using ANN are in good agreement with the actual 
values as the error is less than $1.5 \%$. This error for the hybrid composite is similar to the error obtained for wear loss predicted for a metal matrix composite using $\mathrm{ANN}^{[11]}$. The concept of design of experiments used to arrive at the combination of factors has significantly lead to the effectiveness of the modeling using ANN. As the data used for testing is different from that of training, the accuracy of prediction can be greatly appreciated. The SEM (Fig. 3) of the worn surface reveals grooves and debris. The sharp asperities present on the contact surfaces, when coming into contact lead to either plastic deformation or elastic contact. Plastic deformation takes place except at the reinforcements where fracturing takes place. This fracture leads to availability of debris.

\section{CONCLUSION}

In this study, a neural network has been designed to predict the effect of the size and percentage by weight of both flyash and $\mathrm{SiC}$ reinforcements on the wear loss of LM6 aluminium alloy. The prediction is found to be accurate as can be seen from the verification of test results. Further the time consuming and costly experimental process can be avoided.

\section{ACKNOWLEDGEMENT}

The authors acknowledge the management of Kumaraguru College of Technology for the financial support received for the project. Also the facilities extended at PSG College of Technology and Anna University, Chennai are acknowledged.

\section{REFERENCES}

1. Natarajan, N., S. Vijayarangan and I, Rajendran, 2006. Wear behavior of $\mathrm{A} 356 / 25 \mathrm{SiC}_{\mathrm{p}}$ aluminium matrix composites sliding against automobile friction material. Wear, 261: 812-822. DOI:10.1016/j.wear.2006.01.011

2. Rohatgi, P.K. and R.K. Guo, 1997. Mechanism of abrasive wear of $\mathrm{Al}-\mathrm{Si}$ hypoeutectoid alloy containing 5 vol \% fly ash. Tribol. Lett., 3: 339347. DOI:10.1023/A:1019109911923

3. Ramachandra, M. and K. Radhakrishna, 2005. Synthesis-microstructure-mechanical propertieswear and corrosion behavior of an $\mathrm{Al}-\mathrm{Si}(12 \%)$ Flyash metal matrix composite. J. Mater. Sci., 40: 5989-5997. DOI:10.1007/s10853-005-1303-6
4. Tjong, S.C., S.Q. Wu and H.C. Liao, 1997. Wear behaviour of an $\mathrm{Al}-12 \% \mathrm{Si}$ alloy reinforced with a low volume fraction of $\mathrm{SiC}$ particles. Composites Sci. Technol., 57: 1551-1558. DOI:10.1016/S02663538(97)00074-2

5. Chai-Yuan and Su-Jien Linh, 1996. Particle size effects on the abrasive wear of $20 \mathrm{vol} \%$ $\mathrm{SiC}_{\mathrm{p}} / 7075 \mathrm{Al}$ composites. Scripta Mater., 35: 12711276. DOI:10.1016/1359-6462(96)00291-6

6. Zamzam, M., D. Ros and J. Grosch, 1993. Fabrication of $\mathrm{P} / \mathrm{M}$ in situ fibre composite materials part-I. Key Eng. Mater., 79-80: 235-246. DOI:10.40280/0-87849-652-1.235

7. Lee, J.C., J.Y. Byun, C.S. Oh, H.I. Lee and H.K. Seok, 1997. Effect of various processing methods on the interfacial reactions in $\mathrm{SiC}_{\mathrm{p}} / 2024 \mathrm{Al}$ composites. Acta Mater., 45: 5303-53125. DOI: 10.1016/S1359-6454(97)84851-3

8. Cook, A.J. and P.S. Werner, 1991. Pressure infiltration casting of metal matrix composites. Mater. Sci. Eng. A 144: 189-206. DOI:10.1016/0921-5093(91)90225-C

9. Seyad Reihani, S.M., 2006. Processing of squeeze cast Al6061-vol30\% SiC composites and their characterization. Mater. Des., 27: 216-222. DOI:10.1016/j.matdes.2004.10.016

10. Necat Altinkok and Rasit Koker, 2006. Modelling of tensile and density properties in particle reinforced metal matrix composites by using neural networks. Mater. Des., 27: 625-631. DOI:10.1016/j.matdes.2005.01.005

11. Hulya Kacar Durmus, Erdogan Ozkaya and Cevdet Meric, 2006. The use of neural networks for the prediction of wear loss and surface roughness of AA 6351 aluminium alloy. Mater. Des., 27: 156159. DOI:10.1016/j.matdes.2004.09.011

12. Cochran W.G. and Cox G.M., 1957. Experimental Designs. 2nd Edn., John Wiley and Sons, Canada.

13. Ferhat Gul and Acilar Mehmet, 2004. Effect of the reinforcement volume fraction on the dry sliding wear behaviour of $\mathrm{Al}-10 \mathrm{Si} / \mathrm{SiCp}$ composites produced by vacuum infiltration technique. Compos. Sci. Technol., 64: 1959-1966. DOI:10.1016/j.compscitech.2004.02.013

14. Rasit Koker, Necat Altinkok and Adem Demir, 2007. Neural Network based prediction of mechanical properties of particulate reinforced metal matrix composites using various training algorithms. Mater. Des., 28: 616-627. DOI:10.1016/j.matdes.2005.07.021 